\title{
Technology-enabled Learning (TEL): YouTube as a Ubiquitous Learning Aid ${ }^{1}$
}

\author{
Mohamed Ahmed Mady and Said Baadel
}

\begin{abstract}
The use of social networks such as Facebook, Twitter, and YouTube in the society has become ubiquitous. The advent of communication technologies alongside other unification trends and notions such as media convergence and digital content allow the users of the social network to integrate these networks in their everyday life. There have been several attempts in the literature to investigate and explain the use of social networks such as Facebook and WhatsApp by university students in the Arab region. However, little research has been done on how university students utilize online audiovisual materials in their academic activities in the UAE. This research aims to elucidate the use of YouTube as a learning aid for university students in the UAE. We adopt the technology acceptance model (TAM) as the theoretical framework for this investigation. A quantitative methodology is employed to answer the research question. Primary data consisting of 221 correspondents were analyzed, covering patterns of using YouTube as an academic audiovisual learning aid. Statistical techniques including descriptive, correlations, regression tests were used to analyze the data. The study concluded that students use YouTube as a learning tool for their academic studies and enriching their general knowledge; and there is a positive relationship between the use of YouTube videos in academic settings and the students' overall performance. This study can shed light for teachers, curriculum designers, government entities, and other stakeholders on how to best utilize and integrate the online technology - YouTube - as a learning aid.
\end{abstract}

Keywords: Audiovisual learning; Online learning; Technology acceptance model; Technologyenabled learning; YouTube;

\footnotetext{
${ }^{1}$ Preprint of an article published in [Journal of Information \& Knowledge Management, Vol. 19, No. 1 (2020) 2040007 (16 pages)] [Article DOI: 10.1142/S0219649220400079] @ [copyright World Scientific Publishing Company] [Journal URL: https://www.worldscientific.com/worldscinet/jikm]

Cite as: Mady, M. A. and Baadel, S. (2020). Technology-enabled Learning (TEL): YouTube as a Ubiquitous Learning Aid. Journal of Information \& Knowledge Management, Vol. 19, No. 1 (2020), 1-16.
} 


\section{Introduction}

Higher education institutions today adopt and integrate e-learning materials, courses and programs that are facilitated by cutting-edge multimedia tools, and audio-video features in online platforms (Manadhata \& Wing, 2011). Kleinman and Dwyer (1999) assert that using specific visual skills in terms of colors is more effective in producing the learning process as opposed to using black and white materials. Game-based inspired learning and watching and interacting with audiovisual materials can improve the students' learning process (Majeed, et al., 2017). The students' understanding levels tend to increase through the processes of watching, hearing and producing in instructional context to reach $75 \%$. This is higher than $40 \%$, when the students only watch and hear, or $20 \%$ for hearing only (DeWitt et al., 2013).

Liu, Liao, \& Pratt (2009) confirm that the presentation of learning materials in the most media-rich format (audio, video, and text) is most likely to be accepted by users, as it "always generates higher level of PU (Perceived Usefulness) and concentration than text-audio-based or audio-video-based presentations." (P. 606).

Berk (2009) explains that in watching videos both hemispheres of the brain are used; the left hemisphere processes the verbal contents and the right processes the visual contents. This is done by using $85 \%$ of the brain capacity to understand videos, which makes the realization process more straightforward than other types of materials such as audio or textual materials. He adds that video materials trigger the three core intelligences of the student's brain. They are "verbal/linguistic and visual/spatial, and even musical/rhythmic" (P. 3).

Ubiquitous computing has been used to create smart classrooms in some technological advanced educational environments. In ubiquitous computing, information is communicated through a combination of sensors and processors that are embedded in various physical objects that form a network (Sing and Kaur, 2014). However, such systems are generally too expensive, time-consuming, and do require vast expertise and know-how to develop. On the other hand, digital audio with a simple video (audiovisual) recorded and uploaded in social websites such as Facebook or YouTube is a cheaper alternative and simpler to produce and manipulate. Thus, YouTube represents great potentials as a learning aid for learners and teachers in higher education. According to Baadel, et al. (2017), YouTube is the most used and preferred technology by faculty in the classroom. 
Further, YouTube provides massive amounts of educational materials for learners and teachers. This goes through thousands of user-generated YouTube channels covering various topics at school and university levels. YouTube EDU is a channel that features the know-how knowledge, tutorials, and lessons for learning skills and concepts. The channel is organized in playlists to offer a series of video tutorials and lectures in different areas in social and natural sciences. YouTube Teachers is another example that allows teachers to view and upload their lessons and tutorials.

In this paper, we aim to investigate the use of YouTube as an online audiovisual platform by university students in the UAE. The research framework considers the students' perceptions and uses of YouTube as a complementary learning tool. We primarily focus on the learning aspect within the academic contexts. A second emphasis of this study is about the students' use of YouTube as a learning resource to enrich their general knowledge outside the academic settings.

Based on previous research (e.g., Moghavvemi et al., 2018; Chintalapati \& Daruri, 2017; Orús et al., 2016), and based on our professional experience and observations as teachers, we started the inquiry of this research with a foundational assumption that university students in the UAE use YouTube as a learning tool. In so doing, we adopt a postpositivist epistemological belief about the uses and gratifications of YouTube by the students (Guba \& Lincoln, 2005; Lincoln, Lynham, Guba, 2011). We attempt to discover and approximate the reality of the situation by answering the following research questions:

1- How do university students in the UAE use YouTube as a learning aid for academic studies?

2- How do they use YouTube to enrich their general knowledge?

3- How useful do students consider YouTube as a source of information?

4- Does watching learning materials on YouTube positively influence the students' academic performance in terms of grades?

To answer these questions and conduct the research, we employ the technology acceptance model (TAM) (Davis, 1989) as the theoretical framework for this study.

The remainder of the paper is structured in 4 additional sections. In section 2, we provide a background review of the literature in the field, including the theoretical framework of the study. The 
research methodology is highlighted in Section 3, followed by the Analysis and Discussion in Section 4. Finally, Section 5 concludes the paper.

\section{Background Review and Theoretical Framework}

Since its establishment in 2005, YouTube has been hosting millions of online audiovisual materials. Presently, YouTube is considered the largest online video sharing website with a wide verity of contents in social, cultural, scientific, and entertainment aspects (Brandwatch, 2019). As of May 2019, there are over 500 hours of videos being uploaded to YouTube every minute, coming up from 6 hours every minute in 2007 (Statista, 2019). This puts YouTube in the second position of the most visited websites on the Internet after Google and surpassing Facebook (Brandwatch, 2019). According to a survey done by Northwestern University in Qatar, half of the Arab nationals use YouTube regularly (Northwestern University in Qatar, n.d.).

In general, the main gratification of YouTube is to satisfy the users' entertainment needs (Haqqu, Hastjarjo, \& Slamet, 2019; Balakrishnan \& Griffiths, 2017). For leaners, the impulsive use of YouTube by university students is considered to be stronger towards the entertainment purpose rather than the information purpose (Klobas et al., 2018). However, the integration of YouTube in higher education specifically in the classroom has been rapidly growing, as it is considered an effective tool for learning (e.g., Fleck et al., 2014; Buzzetto-More, 2015; Barry et al., 2016; Orús et al., 2016; Baadel, et al., 2017; Jill, Wang, \& Mattia, 2019).

Reviewing the literature reveals various examples of the usefulness of YouTube as a learning tool in several fields. For example, exploring the role of YouTube in providing psychoeducation about schizophrenia, Lam, Tsiang, and Woo (2017) conclude that YouTube is a significant avenue not only in providing such type of education, but also in disseminating and delivering the videos anonymously for who would fear facing negative public stigma toward schizophrenia. YouTube has been found to be an effective medium to deliver medical instructions about male urethral catheterization (Nason et al., 2015). Jones \& Cuthrell (2011) argue that the interactive facility on YouTube through commenting on videos can develop the students' language skills. From a teaching perspective, teaching presence is a vital element for students' engagement (Dixson, 2010). This engagement can be achieved through offering audiovisual learning materials that are available online for students. In turn, this can trigger students' attention and motivate them to learn (Berk, 2009). 
It has been argued that utilizing social networks helps to build stronger connections between the university and students for various purposes, such as developing social capital, facilitating active learning, and marketing (Irwin al et., 2012; Bosch, 2009; Constantinides, \& Zinck Stagno, 2011). Many universities have been prompted to build their presence on YouTube by creating their own channels with the objective of developing better student/teacher relations and communications through coordinated efforts and real-time interactions and feedback (Moghavvemi, et al., 2018). From a business viewpoint, higher education institutions tend to create and utilize YouTube channels to market and publicize their programs and degrees (Pham, al et., 2017). This notion is supported and boosted by the maximum mobility, availability, and interactivity of the online content on the social network, which pushes more and more universities worldwide to realize the benefits of utilizing YouTube as a free marketing channel.

Accessing YouTube on-campus can be an obstacle in some universities, as many schools put up firewalls to block YouTube and other social networks. While this prevents inappropriate materials from being played/seen on campus, it blocks a wide range of educational materials (Jones \& Cuthrell, 2011). Additionally, due to its very high penetration into society and the academic sphere, YouTube can be potentially harmful if wrong, misleading, or not useful information is disseminated on the platform. Azer et al. (2012) find that 53\% of the uploaded videos on YouTube in one month (November to December 2011) with relevant information about the clinical examination of the nervous system are not educationally useful. Another disadvantage of using YouTube videos in learning is the challenge of finding the right materials/information among a massive amount of content addressing the searched topic (Sherer \& Shea, 2011). Despite the fact that YouTube utilizes the powerful search engine of Google, the search results often reveal many options that can be confusing for teachers who intend to incorporate proper videos to their lectures.

We adopt the Technology Acceptance Model (TAM) as the theoretical framework underpinning this study. The concept of TAM was first introduced based on an adaptation to the theory of reasoned action (TRA) (Davis, 1985). The TRA hypothesizes that measuring the behavioral intention of any action can predict the choice for this action. The TRA explains the users' determinants in choosing a wide range of tools in a verity of domains by measuring their behavioral actions (Sheppard, Hartwick, Warshaw, 1988). Similarly, but with a specific focus on computers, the TAM predicts and explains the user's behavior in using technology by measuring the determinants of users' acceptance of this technology. As shown in Figure 1, the TAM is based on two primary benefits that the users expect to 
gain. First is the Perceived Usefulness (PU) that is defined as the probability of the user's subjective judgment on using a specific computer application that can increase his or her performance. Second is the perceived ease of use (EOU) that refers to the user's expectations of a system to be effort-free. Both key benefits control and predicts the user's behavioral attitude towards technology (Davis, Bagozzi, Warshaw, 1989).

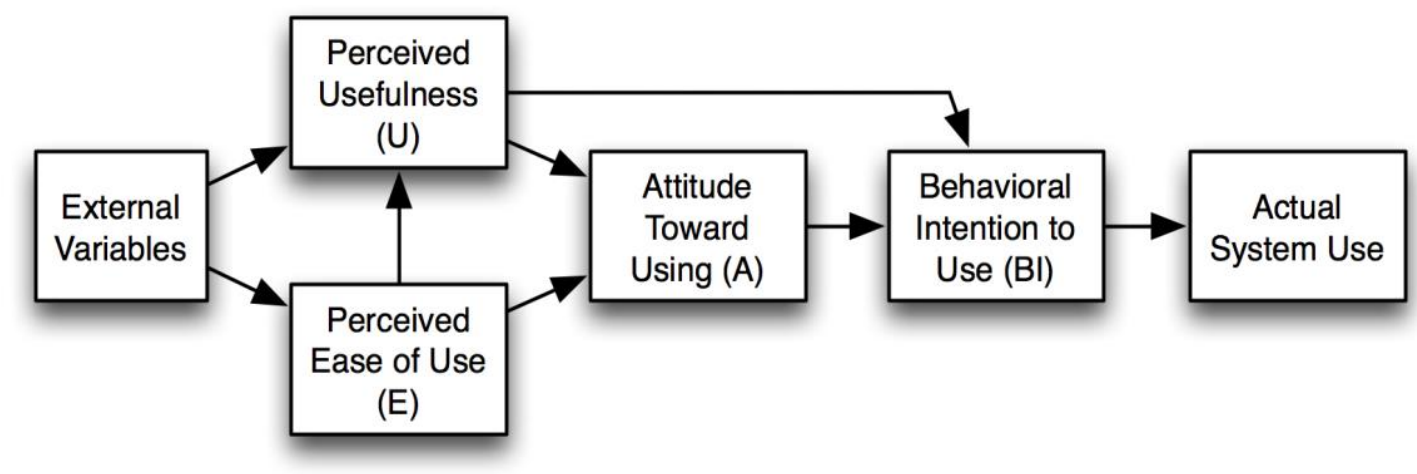

Fig. 1. TAM theoretical framework

\section{Methodology}

Based on the researchers' postpositivist paradigm and based on the adoption of TAM as the theoretical framework, a quantitative research methodology is employed to investigate the students' uses of YouTube as a learning aid.

The main objective of this study is to investigate the students' uses of YouTube for the academic purposes and for developing and improving their general knowledge, and how this influences their perceptions of YouTube and their academic standings. In so doing, we try to investigate four main concepts 1- the students' usability of YouTube as learning tool; 2- the easiness \& usefulness of YouTube for students; 3- the students' sociability in using YouTube as a learning aid; and 4- the influence of using YouTube on the students' grades.

Based on the theoretical and conceptual approach presented in the TAM, and based on the research objectives as stated above, we hypothesize the following:

H1 - There is a positive relationship between the perceived usefulness and the student's adoption of YouTube as a learning tool. 
$\mathrm{H} 2$ - There is a positive relationship between the ease of use and the students' adoption of YouTube as a learning tool.

H3 - There is a positive relationship between the students' sociability within studying context and their uses of YouTube as a learning tool.

H4 - There is a positive relationship between the students' grades and their uses of YouTube as a learning tool.

The primary data of the research instrument consisting of 24 items were collected via a distributed questionnaire to the participants through personal interviews (i.e., face-to-face communication). The questionnaire consisted of general demographic questions to be used in the descriptive analysis followed by a combination of closed-ended questions with Yes/No and a five Likert scale $(1=$ strongly agree, 2 = agree, $3=$ neutral, 4 = disagree, $5=$ strongly disagree) questions to assess the participants' uses, gratifications and preferences of using YouTube as a learning aid.

Since the data was collected using only a single medium, i.e., the personal interview technique (faceto-face), the chances that the results may be influenced by the common method bias problem was taken into consideration. Precautionary steps were taken during the data collection process to minimize this problem. First, all respondents were assured about their confidentiality, full anonymity,

and protection of their privacy throughout the survey phase. Secondly, dependent variables were asked after to the independent variables in an effort to minimize the likelihood of respondents deliberately matching their responses from each other in a classroom setting. This technique minimizes the socially desirable responding likelihood (Podsakoff, et al., 2003).

A Cronbach's Alpha test was performed to check the reliability of the instrument (Wimmer \& Dominick, 2008). The instrument was found reliable with a coefficient of (0.70).

\section{Analysis and Discussion}

First, we run descriptive tests to draw a comprehensive picture of the research sample and depict the uses of YouTube by the respondents in relation to the research questions. Then we utilized correlation analyses to detect the relation and strength between variables. 
Table 1 Participants Profiles $(N=221)$

\begin{tabular}{|c|c|c|c|}
\hline Variable & Categories & Frequency & Percentage \\
\hline \multirow[t]{4}{*}{ Age } & $15-17$ & 21 & 9.5 \\
\hline & $18-24$ & 189 & 85.5 \\
\hline & $25-34$ & 8 & 3.6 \\
\hline & $35-45$ & 3 & 1.4 \\
\hline \multirow[t]{2}{*}{ Gender } & Male & 70 & 31.7 \\
\hline & Female & 151 & 68.3 \\
\hline \multirow[t]{2}{*}{ Emirate of Study } & Dubai & 150 & 67.9 \\
\hline & Abu Dhabi & 71 & 32.1 \\
\hline \multirow[t]{6}{*}{ Academic Ranking } & 1st year & 66 & 29.9 \\
\hline & 2nd year & 27 & 12.2 \\
\hline & 3rd year & 77 & 34.8 \\
\hline & Graduating & 42 & 19 \\
\hline & Graduated & 5 & 2.3 \\
\hline & Master studies & 4 & 1.8 \\
\hline \multirow[t]{9}{*}{ Degree Major } & Engineering & 4 & 1.8 \\
\hline & Communication & 43 & 19.5 \\
\hline & Design & 1 & 0.5 \\
\hline & Business & 92 & 41.6 \\
\hline & Medicine & 2 & 0.9 \\
\hline & Computer & & \\
\hline & Sciences & 1 & 0.5 \\
\hline & Education & 72 & 32.6 \\
\hline & Other & 6 & 2.7 \\
\hline
\end{tabular}

Table 1 above highlights the participants' profiles in the study. They were undergraduates and graduates from two universities operating in the two emirates of Dubai and Abu Dhabi, in the UAE. Given the research population that exceeds 20000 students, a convenient sample of 262 participants was initially targeted. After eliminating the missing and invalid variables, a total number of 221 valid responses was retained. This represents a response rate of $84 \%$. 
As Table 1 shows, almost $32 \%$ of the convenient sample are males and $68 \%$ are females. The participants from the two universities were distributed as almost $70 \%$ from the university in Dubai, and 30\% from the university in Abu Dhabi. The majority of the respondents are in the $3^{\text {rd }}$ year $(34.8 \%$, $\mathrm{n}=77)$ and in the $1^{\text {st }}$ year $(29.9 \%, \mathrm{n}=66)$. The age group of 18-24 represents the majority of the sample size $(85.5 \%, \mathrm{n}=189)$ followed by a younger group of $15-17$ years old $(9.5 \%, \mathrm{n}=21)$. Students majoring in Business represent the largest group in sample $(41.6 \%, \mathrm{n}=92)$ followed by Education majors $(32.6 \%, \mathrm{n}=72)$.

\subsection{The Usability of YouTube as A Learning Aid}

To investigate the students' perceptions and uses of YouTube as a learning aid, we performed several descriptive analyses. First, after running a Chi-Square tests on nominal variables, we found no significant association between the respondents' gender, major, attended university, and academic ranking and their use YouTube as an aid in their academic learnings and general knowledge acquisition. However, as Figure 2 shows, a total of $90.5 \%$ of the sample size responded that YouTube is their main online platform for viewing videos. Further, older age groups, between 25 and 45 years old, showed more agreement on using YouTube (100\%) than the younger groups between 17 and 24 years old $85.7 \%$ \& $90.5 \%$ respectively. The negative responses of considering YouTube the primary source of online videos were found in the groups of younger ages $(n=27)$ who tend to use other online platforms such as Facebook, Snapchat, Instagram, Daily and others as depicted in Figure 3 below.

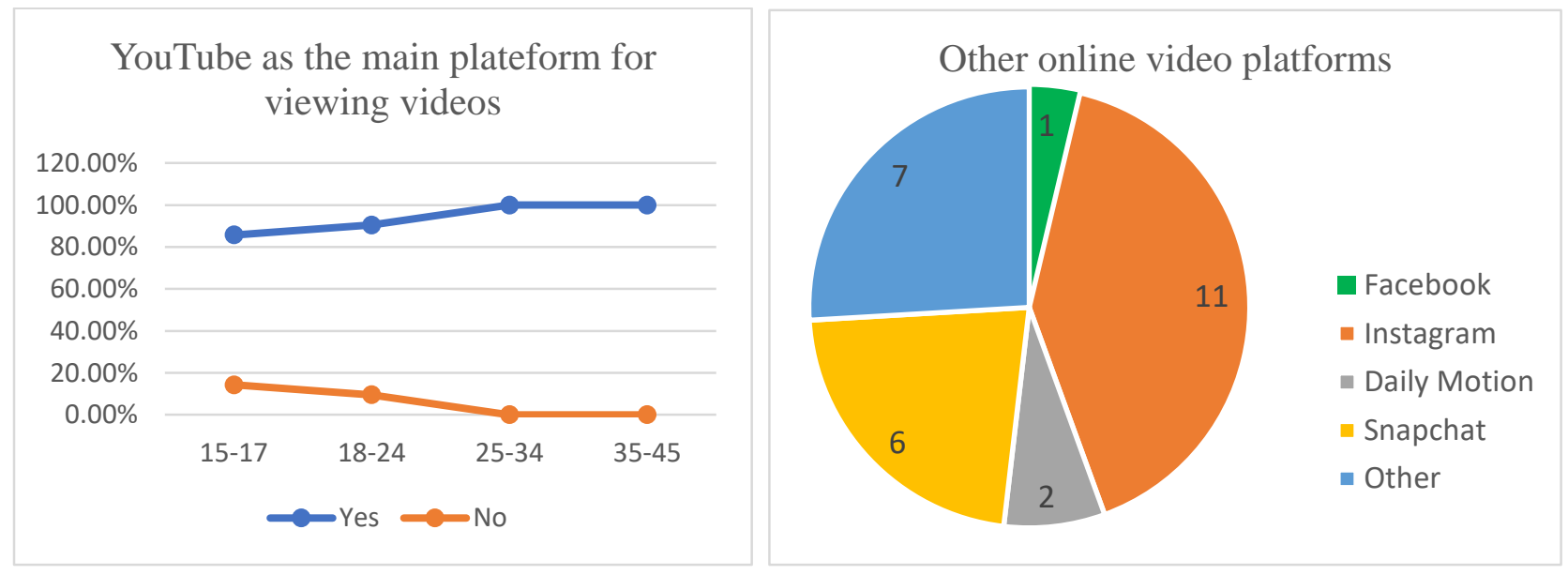

Fig. 2 YouTube as the primary platform based Fig. 3. Other primary platforms besides YouTube on age groups

Exploring the participants' perceptions of YouTube as their primary source for learning audiovisual 
materials, $66.5 \%$ of the sample responded with agree and strongly agree. As shown in Figure 4, the males' positive responses (70\%) was slightly higher than the females' positive responses (64.9\%). This can indicate that males are somehow more dependent on YouTube videos for learning than females.

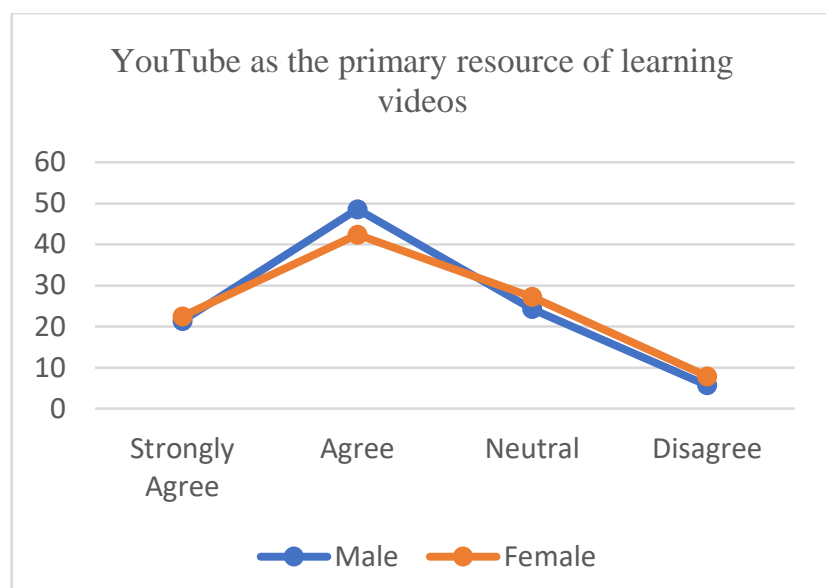

Fig. 4 YouTube as the primary source based on gender

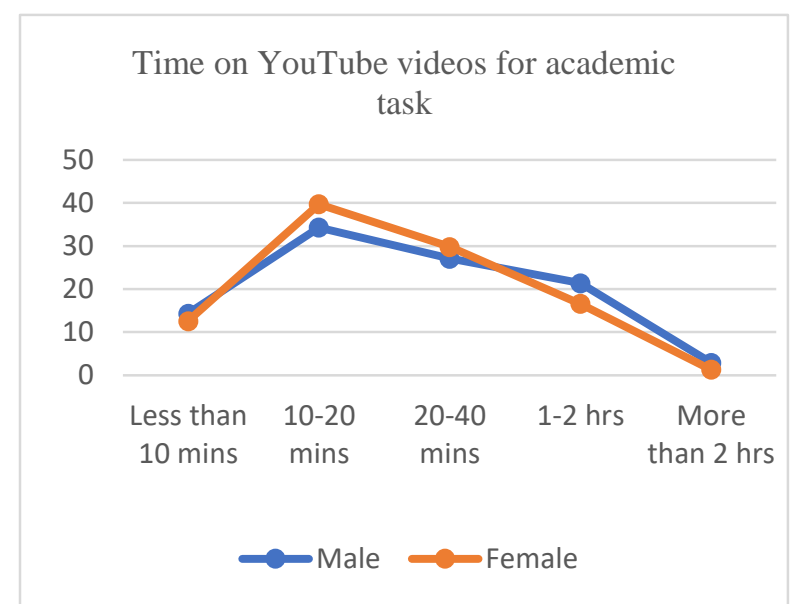

Fig. 5 Average time spent on YouTube to do one academic task

Despite the males' positive tendency of to perceive YouTube as the primary online source for learning videos, the female participants scored higher in the average time spent watching YouTube videos to do one academic task. Figure 5 above shows a cumulative percentage of females' time on YouTube $82.1 \%$ within range of less than 10 minutes to 40 minutes. While the males' percentage was $75.7 \%$. This can imply more attention and persistence of the female respondents in using YouTube as an aiding tool in their academic tasks.

Based on the academic ranking, the graduating students scored the highest cumulative percentage in using YouTube for academic tasks at least once per week (76.2\%), followed by first-year students where $75.8 \%$ of them confirmed using YouTube in the same context as shown in Figure 6. This was followed by third year students, and second year students scoring (71.4\% \& 63\%) respectively as shown in Figure 6 below. We justify the relatively low score of the second-year group (63\%) due to their perception of the usefulness of YouTube in their studies, which was also relatively low (74\%) comparing to the other groups $\left(1^{\text {st }}\right.$ year $=89.4 \% ; 3^{\text {rd }}$ year=88.3\%; Graduating $\left.=85.7 \%\right)$. 


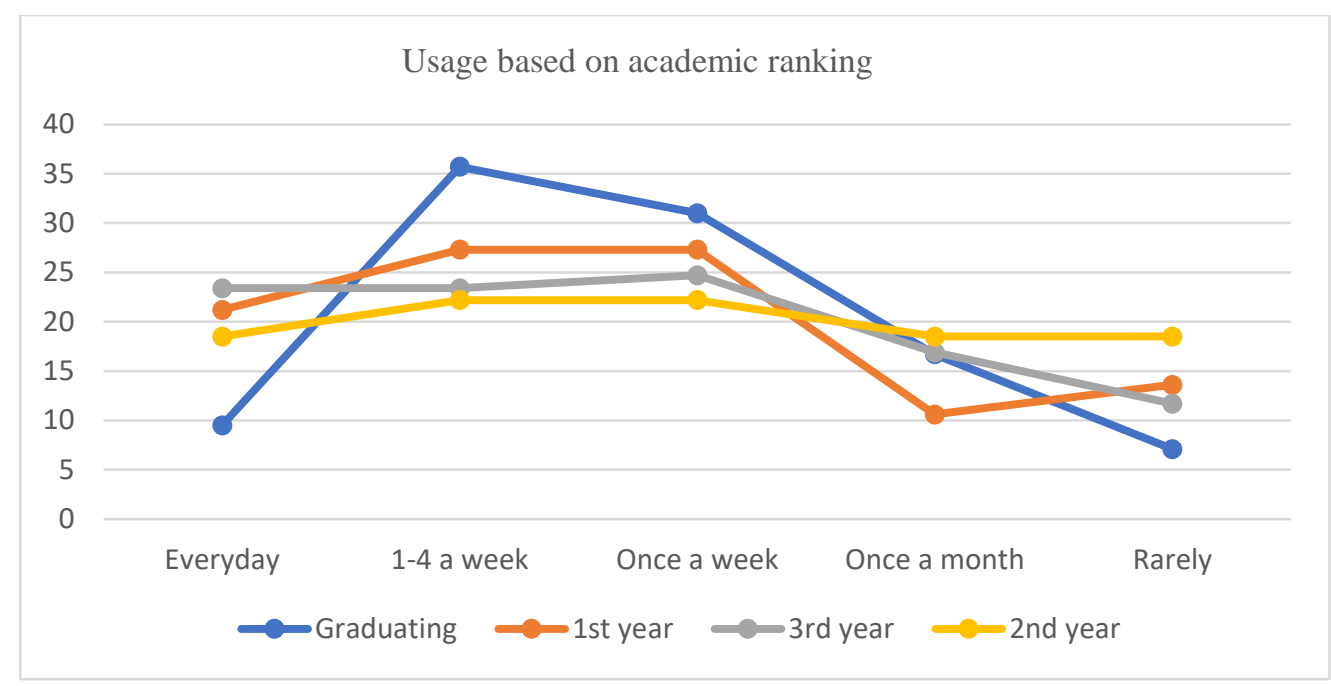

Fig. 6 Academic Ranking based on YouTube usage

We found the top three majors in the sample who use YouTube as a learning aid in their academic studies at least once per week are Business, Education, and Communication with cumulative percentages of $79.3 \%, 72.2 \%$, and $60.5 \%$ respectively as shown in Figure 7.

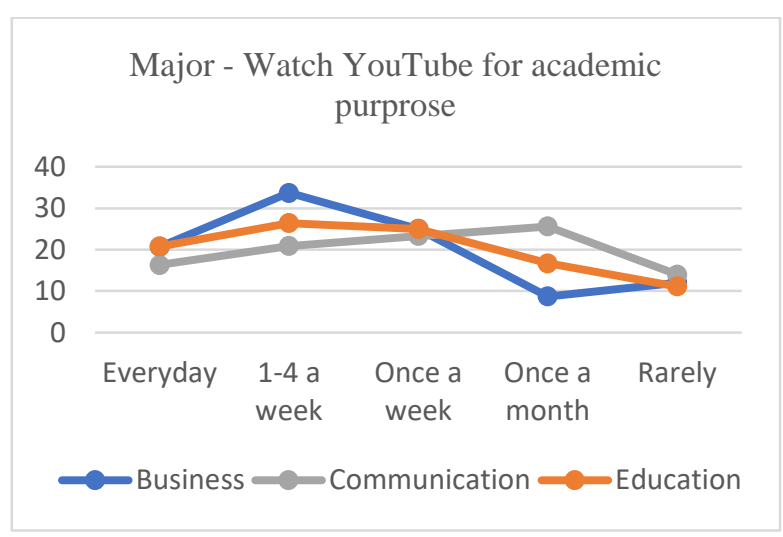

Fig. 7 Using YouTube to search for information for academic studies

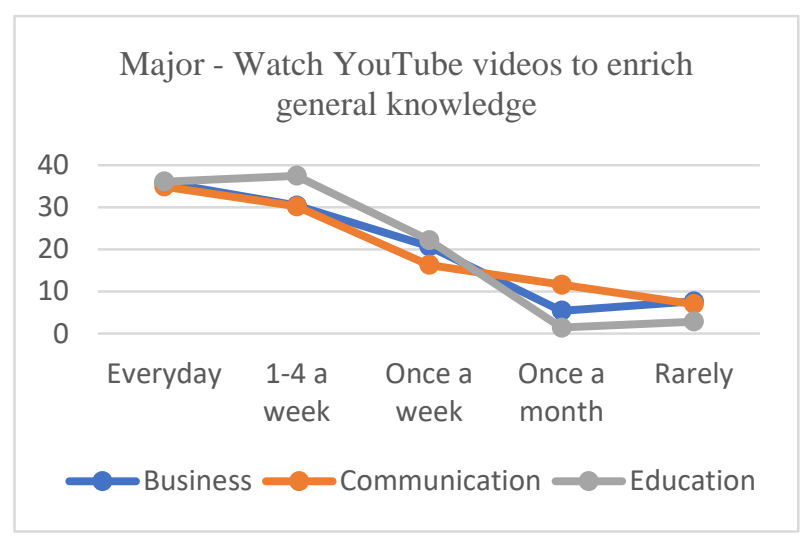

Fig. 8 Frequency of using YouTube to enrich your general information

In watching YouTube videos to enrich general knowledge, the scores of the three primary majors (Business, Communication, \& Education) highlighted in figure 8 were generally higher than the equivalent scores in watching YouTube for academic purposes. The Education majors came first, with $95.8 \%$ of the participants watched YouTube at least once per week to enrich their general knowledge. This is followed by Business then Communication majors. 
Interestingly, there was a moderate negative correlation between how often the students visit YouTube for studying purposes and the amount of time spent on each visit with a confidence level of $99 \%$, where $r=-0.263 ; \mathrm{p}<0.01$. Similar value was found in the correlation between visiting YouTube to acquire general knowledge and time spent per visit, where $r=-0.246 ; p<0.01$. Despite the weakness of the coefficients, there is an indication that for some students visiting YouTube more often would minimize the time they spend on the network per visit; the more they visit YouTube for academic or general knowledge purposes, the less time they will spend in each visit. This can be an indicator for teachers and educators about the students' learning preferences of the proper duration of the videos posted on YouTube.

\subsection{YouTube Easiness and Usefulness as a Learning Aid}

By calculating the Eta squared value in a one-way ANOVA test, we found no significant effect of the independent variables of age, gender, major, university, \& academic ranking on the participants' perception of the easiness of searching YouTube for learning videos. However, the cumulation of positive responses (strongly agree; agree) represented $82 \%$ of the sample size.

Figure 9 depicts the cumulative positive responses about the easiness of searching YouTube for learning videos compared to other online platforms. It is important to mention that the positive responses from the age group of 18-24 represented $70 \%$ of the sample size, which tells that the majority of the participants perceive easiness in searching YouTube for learning videos.

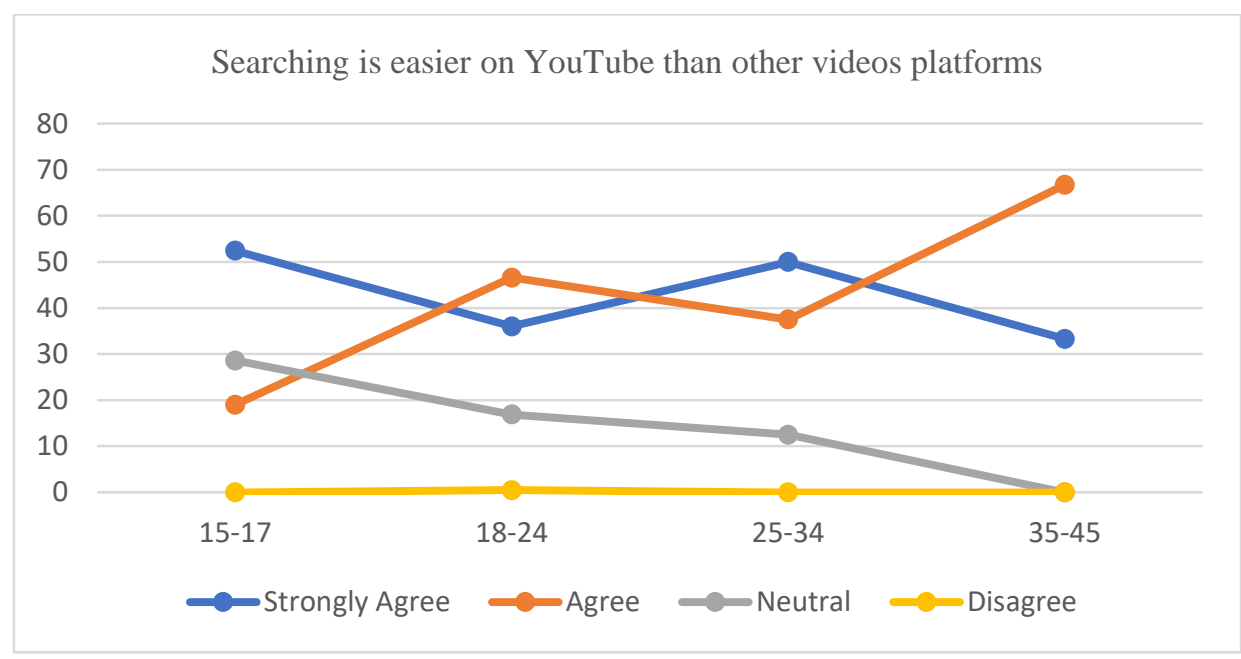

Fig. 9. YouTube search easiness as compared to other platforms 
In addition, there was an average positive correlation between how easy the respondents found the search on YouTube for learning videos and their perceptions of the usefulness of using YouTube in their studies, where $r=0.444 ; p<0.01$. This indicates that the faster and easier the students find proper learning videos that related to their subjects, the more they perceive YouTube as a useful and the more likely they will use it as a learning tool.

Similarly, there was a moderate positive correlation between the respondents who find learning from videos to be more helpful than written materials and the respondents who perceive YouTube easy to search for learning videos, where $r=0.351 ; p<0.01$. This refers to the possibility that some students become more dependent on learning videos from YouTube rather than written materials, given that they can easily find the right videos for their academic studies. In the same context, there was a moderate positive correlation between the easiness perceptions of YouTube and the students' consideration of YouTube as the primary source for learning videos, where $r=0.353 ; p<0.01$. Another positive correlation was found between the students' perceptions of YouTube as a helpful tool and their perceptions of YouTube learning videos as more entertaining than written materials. Similarly, an average positive correlation was found between how helpful using YouTube in their studies and how helpful it will be if the students find their instructors' learning materials on YouTube, where $r=0.45 ; p<0.01$.

Based on the previous descriptive analyses explained, and based on the average and moderate correlations detected between variables that measured the participants' perceptions of the easiness and usability of YouTube as a learning tool, we accepted the first two hypotheses in the student about the usefulness and easiness of YouTube as a learning tool.

\subsection{Students' Sociability in Using YouTube as Learning Aid}

We measured the respondents' sociability in reference to their uses of YouTube as a learning tool based on their behaviors of 1- sharing the useful YouTube videos that they find; and 2- asking their colleagues about useful videos they find for learning purposes. Generally, the cumulative positive responses of sharing behavior YouTube videos were $66.6 \%$ of the sample size $(\mathrm{N}=221)$.

In details, as depicted in Figure 10 about sharing YouTube learning videos, the students between 18 and 24 years old scored the highest percentage (55.2\%) among the age groups. The female respondents found to have more sharing behaviors (47.9\%) than male respondents (19\%). The 
students in Dubai university tend to be more sharing of useful videos (42.5\%) than their colleagues in Abu Dhabi university (23.9\%). The highest majors who tend to share learning videos were Business (28.5\%) followed by education $(23.9 \%)$ then communication $(10.4 \%)$. The students in the third year scored the highest sharing behavior $(24.8 \%)$ followed by first-year students $(19.9 \%)$ then graduating students $(12.2 \%)$.

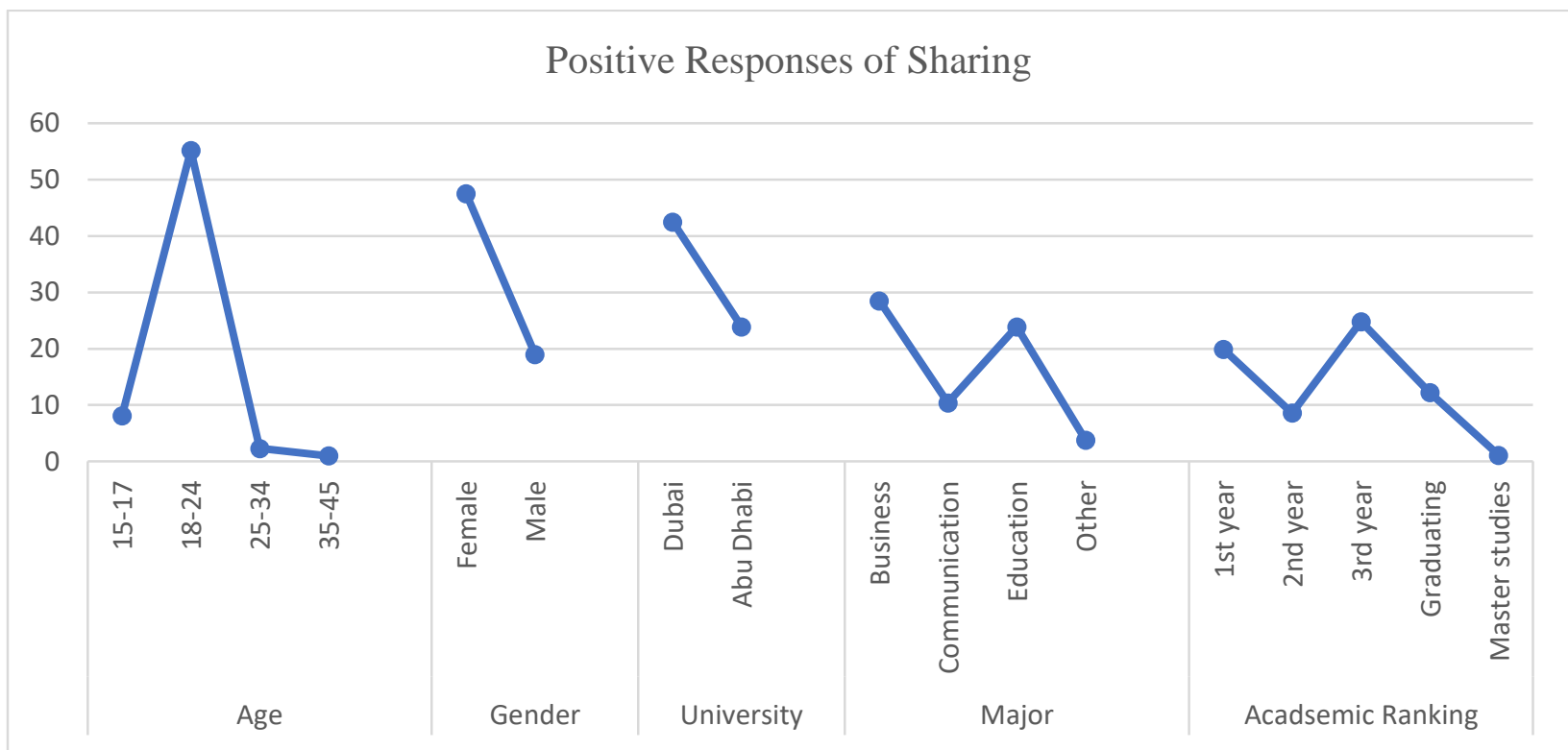

Fig. 10. Participants who share useful YouTube with their colleagues

Further, we found a significant positive correlation between the respondents' sharing behaviors of YouTube videos and their tendency of asking their colleagues if they found useful learning videos on YouTube, where $r=0.40 ; p<0.01$. This can refer to the social activities of sharing and interacting among students while using YouTube as a learning aid and proves the third hypothesis of the study. Based on this analysis, we partially accepted the third hypothesis in the study about the students' sociability and their use of YouTube as a learning tool.

\subsection{YouTube a learning tool and the improvement in the students' grades.}

The descriptive analyses showed that $61 \%$ of the sample believe that watching YouTube learning videos improve their grades. As shown in Figure 11, the positive responses from the female participants (40\%) were almost double the responses from male participants (21\%). Similarly, the participants from the university in Dubai reported 38.2\%, where Abu Dhabi university participants reported $22.8 \%$ of positive answers. The Business majors scored $26 \%$, followed by Education majors 
(22\%) then Communication majors (8.6). The students in third-year reported the highest position opinions of (22\%) followed by first-year students (18\%) then graduating students $(13.2 \%)$.

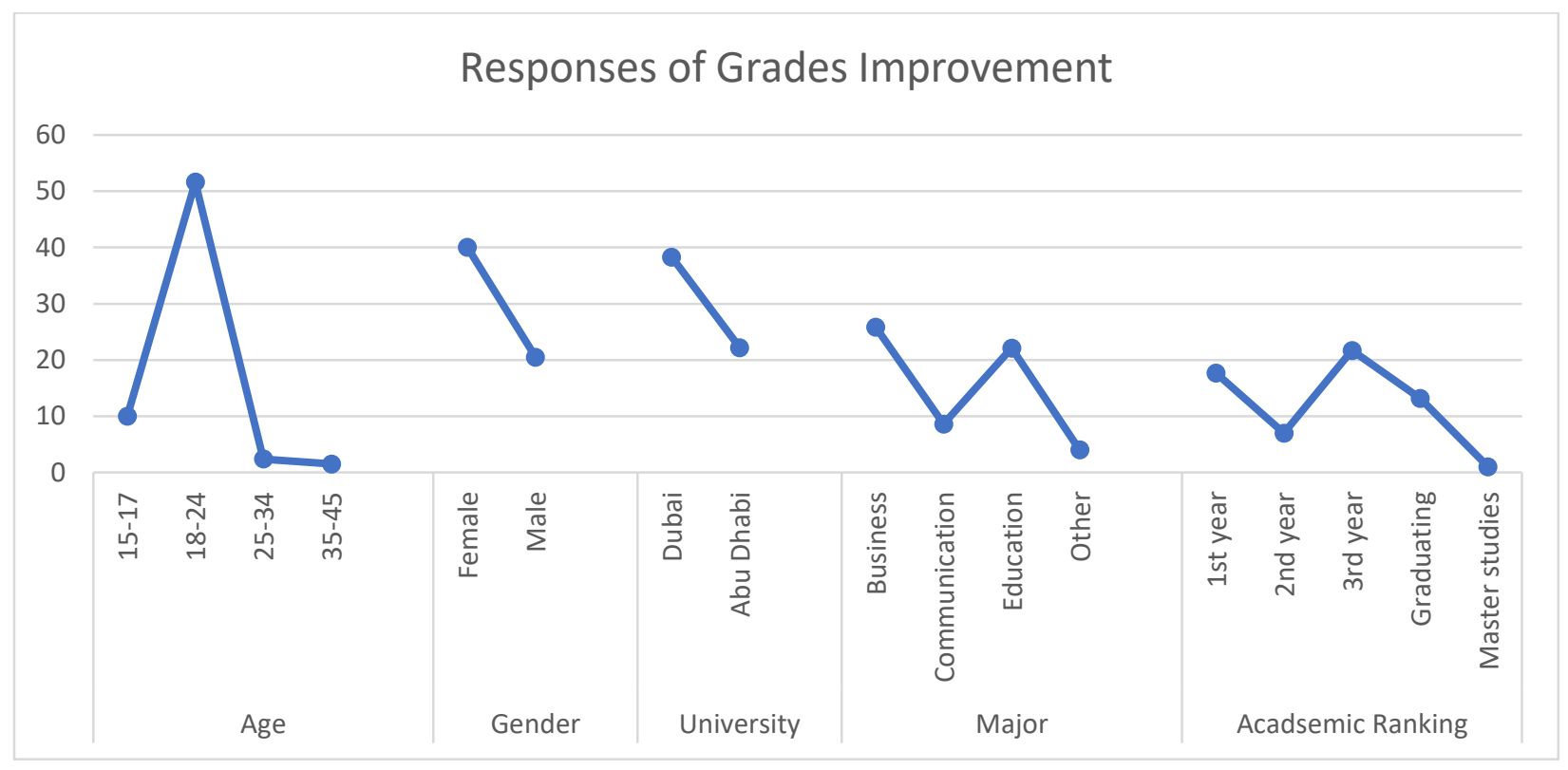

Fig. 11. Participants reporting improved grades by watching YouTube learning videos

Additionally, we found an average position correlation between the participants' perceptions about the usefulness of YouTube in their studies and the improvement of their grades for watching YouTube videos where $r=0.50 ; p<0.01$. Another positive correlation was found between grades improvement by watching YouTube learning videos and how the students find YouTube learning materials more entertaining than written materials where $r=0.43 ; p<0.01$. Similarly, there was a positive correlation between YouTube for improving grades and considering YouTube as the primary source for learning videos where $r=0.44 ; p<0.01$. This indicates the participants' positive views of YouTube as a learning aid and as a tool to improve their grades, which is most likely to occur to some students outside the sample based on the confidence level as reported above. Therefore, we partially accepted the fourth hypothesis about the relation of using YouTube as learning aid and the improvement in students' academic standing in terms of grades.

\section{Conclusion and Future Work}

YouTube has recently been very instrumental in the dissemination of knowledge as it provides massive amounts of educational materials for learners and teachers. In this paper, we investigated the usefulness of YouTube as a learning aid in a post-secondary education setting. We looked at its 
usability, easiness and usefulness, students' sociability in terms of sharing interacting, and improvement of students' grades by watching YouTube learning videos. We collected data from two universities in the UAE based in the emirate of Dubai and Abu Dhabi. We did statistical analysis to validate the hypotheses formulated on the usage of YouTube as a learning aid.

The study found that the more students visit YouTube for academic or general knowledge purposes, the less time they spent on each subsequent visit. It was also indicated that students found easiness and usefulness in using YouTube and were willing to share their findings, thus increasing their sociability and their interactions with their peers. Also, we found that there was a positive impact on the usage of YouTube and student grades. These findings can serve as good indicators for teachers, educators, parents, curriculum developers, government entities, and other stakeholders of the proper duration of learning videos that they can post on YouTube and how best to utilize and integrate the online technology - YouTube - as a learning aid.

There were a few limitations in this study. The data collected was limited to what was collected in the two universities from the two emirates of Dubai and Abu Dhabi. The study could have benefitted from a wider sample from different academic institutions drawing a larger dataset. Also, instances related to secondary level education and institutes of continuing education for career enhancements were missing in this study and could have shed some light on those two different demographics of YouTube users.

Extending on this research, we plan to conduct another study to investigate the university teachers' adoption of interactive and online technologies, e.g. social networks, in the classroom and how this influence the students' learning experience and their levels of engagement and satisfaction of the educational processes. In doing so, we plan to conduct a comprehensive study by adopting a mix methodology of quantitative and qualitative approach to gain more insights of the students' learning patterns and how they align with the applied teaching techniques inside the classroom. 


\section{References}

- Azer, S. A., AlEshaiwi, S. M., AlGrain, H. A., \& AlKhelaif, R. A. (2012). Nervous system examination on YouTube. BMC medical education, 12(1), 126.

- Baadel, S., Majeed, A., and Kabene, S. (2017). Technology adoption and diffusion in the Gulf: Some challenges. In Proceedings of the 8th International Conference on E-Education, EBusiness, E-Management and E-Learning, 16-18, Kuala Lumpur, Malaysia (ACM).

- Balakrishnan, J., \& Griffiths, M. D. (2017). Social media addiction: What is the role of content in YouTube?. Journal of behavioral addictions, 6(3), 364-377.

- Barry, D. S., Marzouk, F., Chulak-Oglu, K., Bennett, D., Tierney, P., \& O'Keeffe, G. W. (2016). Anatomy education for the YouTube generation. Anatomical sciences education, 9(1), 90-96.

- Berk, R. A. (2009). Multimedia teaching with video clips: TV, movies, YouTube, and mtvU in the college classroom. International Journal of Technology in Teaching \& Learning, 5(1), 1-15.

- Bosch, T. E. (2009). Using online social networking for teaching and learning: Facebook use at the University of Cape Town. Communicatio: South African Journal for Communication Theory and Research, 35(2), 185-200.

- Brandwatch. (2019). 52 Fascinating and Incredible YouTube Statistics. Retrieved August 3, 2019, from https://www.brandwatch.com/blog/youtube-stats/

- Buzzetto-More, N. (2015). Student attitudes towards the integration of YouTube in online, hybrid, and web-assisted courses: An examination of the impact of course Modality on Perception. Journal of Online Learning and Teaching, 11(1), 55.

- Chintalapati, N., \& Daruri, V. S. K. (2017). Examining the use of YouTube as a Learning Resource in higher education: Scale development and validation of TAM model. Telematics and Informatics, 34(6), 853-860.

- Constantinides, E., \& Zinck Stagno, M. C. (2011). Potential of the social media as instruments of higher education marketing: A segmentation study. Journal of marketing for higher education, 21(1), 7-24.

- Davis, F. D. (1985). A technology acceptance model for empirically testing new end-user information systems: Theory and results (Doctoral dissertation, Massachusetts Institute of Technology).

- Davis, F. D., Bagozzi, R. P., \& Warshaw, P. R. (1989). User acceptance of computer technology: a comparison of two theoretical models. Management science, 35(8), 982-1003.

- DeWitt, D., Alias, N., Siraj, S., Yaakub, M. Y., Ayob, J., \& Ishak, R. (2013). The potential of Youtube for teaching and learning in the performing arts. Procedia-Social and Behavioral Sciences, 103, 1118-1126. 
- Dixson, M. D. (2010). Creating effective student engagement in online courses: What do students find engaging?. Journal of the Scholarship of Teaching and Learning, 10(2) 1-13

- Fleck, B. K., Beckman, L. M., Sterns, J. L., \& Hussey, H. D. (2014). YouTube in the classroom: Helpful tips and student perceptions. Journal of Effective Teaching, 14(3), 21-37.

- Guba, E. G., \& Lincoln, Y. S. (2005). Paradigmatic controversies, contradictions, and emerging confluence. In N. K. Denzin \& Y. S. Lincoln (Eds.), The Sage handbook of qualitative research. Thousand Oaks: Sage.

- Haqqu, R., Hastjarjo, S., \& Slamet, Y. (2019). Teenagers' Entertainment Satisfaction in Watching Talk Show Program through Youtube. Jurnal The Messenger, 11(1), 38-45.

- Irwin, C., Ball, L., Desbrow, B., \& Leveritt, M. (2012). Students' perceptions of using Facebook as an interactive learning resource at university. Australasian Journal of Educational Technology, 28(7) 1221-1232.

- Jill, M. D., Wang, D., \& Mattia, A. (2019). Are instructor generated YouTube videos effective in accounting classes? A study of student performance, engagement, motivation, and perception. Journal of Accounting Education, 47, 63-74.

- Jones, T., \& Cuthrell, K. (2011). YouTube: Educational potentials and pitfalls. Computers in the Schools, 28(1), 75-85.

- Kleinman, E. B., \& Dwyer, F. M. (1999). Analysis of computerized visual skills: Relationships to intellectual skills and achievement. International Journal of Instructional Media, 26(1), 53.

- Klobas, J. E., McGill, T. J., Moghavvemi, S., \& Paramanathan, T. (2018). Compulsive YouTube usage: A comparison of use motivation and personality effects. Computers in Human Behavior, 87, 129-139.

- Lam, N. H. T., Tsiang, J. T. H., \& Woo, B. K. (2017). Exploring the role of YouTube in disseminating psychoeducation. Academic Psychiatry, 41(6), 819-822.

- Lincoln, Y. S., Lynham, S. A., \& Guba, E. G. (2011). Paradigmatic controversies, contradictions, and emerging confluences, revisited. The Sage handbook of qualitative research, 4, 97-128.

- Liu, S. H., Liao, H. L., \& Pratt, J. A. (2009). Impact of media richness and flow on e-learning technology acceptance. Computers \& Education, 52(3), 599-607.

- Majeed, A., Baadel, S., Williams, M. (2017). Semantics of Intelligent Learning Environment (ILE): Cesim Simulation. Proceedings of the 8th International Conference on E-Education, EBusiness, E-Management and E-Learning. Kuala Lumpur, Malaysia. ACM

- Manadhata, P. K., Wing, J.M. (2011). An Attack Surface Metric. IEEE Transactions on Software Engineering, 37 (3), 371-386. 
- Nason, G. J., Kelly, P., Kelly, M. E., Burke, M. J., Aslam, A., Giri, S. K., \& Flood, H. D. (2015). YouTube as an educational tool regarding male urethral catheterization. Scandinavian journal of urology, 49(2), 189-192.

- Northwestern University in Qatar. (n.d.). MEDIA USE IN THE MIDDLE EAST, 2017. Retrieved August 23, 2019, from http://www.mideastmedia.org/survey/2017/chapter/social-media/

- Orús, C., Barlés, M. J., Belanche, D., Casaló, L., Fraj, E., \& Gurrea, R. (2016). The effects of learner-generated videos for YouTube on learning outcomes and satisfaction. Computers \& Education, 95, 254-269.

- Pham, H. H., Farrell, K., Vu, H. M., Vuong, Q. H., \& Napier, N. K. (2017). Using YouTube video to promote university: a content analysis (No. 17-004). ULB--Universite Libre de Bruxelles.

- Podsakoff, P.M., MacKenzie, S.B., Lee, J.Y. and Podsakoff, N.P. (2003). Common method biases in behavioural research: a critical review of the literature and recommended remedies. Journal of Applied Psychology, 88(5), 879-903.

- Sheppard, B. H., Hartwick, J., \& Warshaw, P. R. (1988). The theory of reasoned action: A metaanalysis of past research with recommendations for modifications and future research. Journal of consumer research, 15(3), 325-343.

- Sherer, P., \& Shea, T. (2011). Using online video to support student learning and engagement. College Teaching, 59(2), 56-59.

- Singh, I., Kaur, J. (2014). Ubiquitous computing: everywhere and anywhere. International Journal of Research in Computer Applications \& Information Technology, 2(3), 01-08.

- Statista. (2019). YouTube: Hours of video uploaded every minute 2019. Retrieved August 23, 2019, from https://www.statista.com/statistics/259477/hours-of-video-uploaded-to-youtubeevery-minute/

- Wimmer, Roger D., Dominick, Joseph R. (2008) Mass media research an introduction. Wadsworth, Cengage Learning. 